\title{
Teacher-Students Verbal Interaction At The Secondary Level
}

Hafiz Muhammad Inamullah, Kohat University, Pakistan

Ishtiaq Hussain, Kohat University, Pakistan

M. Naseer Ud Din, Kohat University, Pakistan

\begin{abstract}
The main purpose of this study was to explore teacher-student verbal interaction in the secondary level classes using the Flanders Interaction Analysis system (FIA). Its findings and conclusions may stimulate teachers at the secondary level to improve their teaching behaviour in order to maximize students' learning.
\end{abstract}

\section{INTRODUCTION}

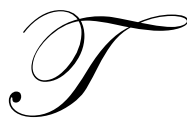

he teaching-learning process at the secondary level in Pakistan is too weak and our classroom environment is totally based on memorization. There is no provision for the development of intellectual and thinking skills among students who are given less time for active participation and interaction, and the teacher seems to have a very dominant role in the class. Unfortunately, a poorly structured classroom quickly deteriorates into a vacuous waste of time (UNDP, 1997).

Based on a large-scale meta-analysis conducted by Walberg (1986), research indicates that the following seven factors are key elements to the effectiveness of teaching: engaged academic learning time, use of positive reinforcement, cooperative learning activities, positive class atmosphere, higher-order questioning, cues and feedback, and use of advance organizers.

Jackson (1968) reports that teachers are typically involved in more than 1,000 verbal exchanges with their students every day. There is a lot of talking, enough to give even the strongest vocal cords a severe case of laryngitis.

Flanders (1963) originally developed a research tool, named the Flanders Interaction Analysis (FIA), which became a widely used coding system to analyze and improve teaching skills.

As a result of research with his coding instrument, Flanders uncovered the two-thirds rule: about twothirds of classroom time is devoted to talking, about two-thirds of this time the person talking is the teacher, and two-thirds of the teacher's talk is "direct" (that is, lecturing, giving directions, and controlling students). The twothirds rule is actually three related two-thirds rules and serves to substantiate that typically teachers verbally dominate the classroom.

Teacher verbal domination of the classroom conditions students to become passive and dependent on the teacher. This dependency has adverse effects on students' attitudes toward learning and students' performance in school. Flanders found that when teachers are trained in his observation technique and become aware of the importance of language in the classroom, their verbal monopoly decreases. To use the Flanders Interaction Analysis, one codes the verbal interaction in one of ten categories in the Flanders Interaction Analysis Coding Instrument (Gay, 2000).

Although this instrument was developed 35 years ago, it was not used in research at any level. In the past three years, a few researches have carried it out in Pakistan to study classroom interaction patterns. There is a need 
to study different patterns of classroom interaction at various educational levels in light of the Flanders Interaction Analysis system.

The present study was designed to investigate teacher-students verbal interaction at the secondary level in light of the Flanders Interaction Analysis system. The study was further delimited to Peshawar only. To achieve the above objective of the study, the following research hypotheses were formulated:

1. About two-thirds of classroom time is devoted to talking at the secondary level.

2. About two-thirds of the talking time, the person talking is the teacher at the secondary level.

3. About two-thirds of the teacher's talk is "direct" at the secondary level.

\section{PROCEDURE}

The following procedure was adopted instead of the previous study by Inamullah et all 2006. The sample of the study consisted of 15 randomly selected classrooms at the secondary level and the number of observed students was 600 at the secondary level. Thus the total number of observed teachers was 25 and the total number of observed students was 600 .

The researcher sat in the classroom for 45 minutes in the best position to hear and see the participants. At the end of each three second period, the researcher decided the category that best represented the communication of events. The researcher wrote down this category number while simultaneously assessing communication in the next period. The researcher continued at the rate of 20 to 25 observations per minute. The researcher's notes were merely a sequence of numbers written in a column, top to bottom, so that the original sequences were preserved (Sampath, K at all.2003).

\section{Data Analysis}

To tabulate these observations in a matrix, the first step was to make sure that the entire series began and ended with the same number. The column was issued for the second number and rows were used for the first number, and the numbers were tallied one pair at a time (Sampath, K at all.2003).

Data collected through the above mentioned research instrument were coded. Each table was analysed and interpreted using percentages. In order to calculate, all the categories from 1 to 10 were added and the mean of 10 categories for 15 secondary classes was calculated. In order to calculate the talk time, frequencies from categories 1 to 9 were added and were converted into percentages by dividing the frequencies with total time of interaction. To calculate the teacher's talk time, frequencies from categories 1 to 7 were added and were converted into percentages by dividing the frequencies with total talk time. To calculate the teacher's direct talk time, frequencies from categories 5 to 7 were added and were converted into percentages by dividing the frequencies with teacher's talk time (tables available from author).

\section{CONCLUSIONS}

On the basis of data analysis and findings of the study, the following conclusions were drawn:

The results reflect that mean talk time (in percentage) in the secondary level classroom was more than twothirds of the total class time. This statement supports the hypothesis; therefore, it was concluded that more than two thirds of the classroom time was used in talking in the observed secondary classrooms as it was concluded by Inamullah et all, 2006.

The mean teachers' talking time (in percentage) in the secondary level classroom was more than two-thirds of the total class time. This statement supports the hypothesis; therefore, it was concluded that more than two thirds of the classroom time was used in teachers' talk in the observed classrooms. 
The mean teachers' direct talking time (in percentage) in the secondary level classroom was more than two-

thirds of the total class time. This statement supports the hypothesis; therefore, it was concluded that more than two thirds of the classroom time was used in teachers' direct talk in the observed classrooms.

\section{REFERENCES}

1. $\quad$ Flander, N. 1963. "Intent, Action and Feed back," A preparation for teaching." Journal of Teacher of Education. New York. Pp251-260.

2. Flander, N. 1967 Teacher Influence in the Classroom. Interaction analysis: theory, research, and application Addison-Wesley. Reading, MA:USA. Pp 103-116.

3. Flander, N. 1970 Analyzing Teacher Behavior. Addison-Wesley. Reading, Mass: P.171.

4. Gay,L R. 2000. Competencies for Analysis and Application ( $5^{\text {th }}$ ed). Educational Research. Florida International University. Pp.448-457.

5. Inamullah,H.M et all.2006.Direct Influence of English teachers in Teaching Learning Process, IER, Kohat University(KUST), Kohat.

6. $\quad$ Jackson, W. P. 1968. Life In Classroom. Hold, Rinehart, New York.P.69.

7. Sampath, K at all.2003.Introduction to Educational Technology. $\left(3^{\text {rd }}\right.$ Ed).Sterling Publisher private Limited, New Delhi-110020 Pp 61-64.

8. $\quad$ UNDP. 1997. Human Development Report. Oxford university press, New York. P.89.

9. Walberg, H. J. 1986. Synthesis of Research on Teaching. In M. C. Witt rock (Ed), Handbook of research on teaching. Paragon. New York. Pp. 214-229. 
NOTES 